\title{
Berberine inhibits colitis-associated tumorigenesis via suppressing inflammatory responses and the consequent EGFR signaling-involved tumor cell growth
}

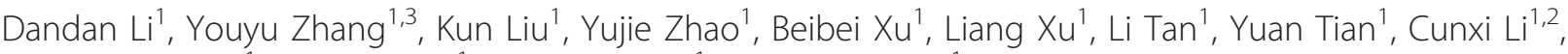 \\ Wenqing Zhang ${ }^{1}$, Hanwei Cao', Yan-yan Zhan ${ }^{1}$ and Tianhui Hu ${ }^{1}$
}

The anti-inflammatory and anti-tumor effects of berberine, a traditional Chinese medicine, were separately discovered in pathological intestinal tissues. However, whether the anti-inflammatory effect of berberine contributes to its anti-tumor effect on colitis-associated colorectal cancer (CACRC) remains unknown. In the present study, we found that berberine effectively inhibited colitis-associated tumorigenesis and colonic epithelium hyperproliferation in dextran sulfate sodium (DSS)-treated $A p c^{\mathrm{Min} /+}$ mice. A mechanistic study identified that these inhibitory effects of berberine occurred through blocking interleukin-6 (IL-6) and tumor necrosis factor-alpha (TNF- $a$ ) expression in colonic macrophages. An in vitro study on cell lines identified that berberine treatment of Raw 264.7 macrophages resulted in conditioned media with fewer proliferative effects on a cell line with a heterozygous Apc mutation (Immorto-Min colonic epithelium, IMCE). EGFR-ERK signaling act downstream of berberine/pro-inflammatory cytokines axis to regulate CACRC cell proliferation. Furthermore, in vivo administration of IL-6 to DSS-treated $A p c^{\mathrm{Min} /+}$ mice effectively weakened the inhibitory effects of berberine on tumorigenesis and EGFR-ERK signaling in colon tissues. Altogether, the results of our studies have revealed that berberine inhibits the development of CACRC by interfering with inflammatory response-driven EGFR signaling in tumor cell growth. The findings of this study support the possibility that berberine and other anti-inflammatory drugs may be beneficial in the treatment of CACRC.

Laboratory Investigation (2017) 97, 1343-1353; doi:10.1038/labinvest.2017.71; published online 31 July 2017

Human inflammatory bowel diseases (IBD), including Crohn's disease (CD), and ulcerative colitis (UC), have become increasingly prevalent since the early 20 th century. ${ }^{1}$

Patients with IBD are often at an increased risk of developing colitis-associated colorectal cancer (CACRC). ${ }^{2-4}$ Inflammation is involved in every step of colon tumorigenesis and development, including cellular malignant transformation, angiogenesis, and metastasis. ${ }^{5}$ Accumulating evidence indicates that genomic alterations, oxidative stress, cytokines, and inflammatory transcription factors may have crucial roles in the development of CACRC. ${ }^{6}$

In chronic inflammation, inflammatory cells produce a variety of pro-inflammatory cytokines and growth factors that stimulate tumor cell proliferation. ${ }^{7}$ Macrophages and dendritic cells initiate innate immune responses by secreting pro-inflammatory cytokines, such as IL-1 $\alpha$, IL-6, IL-1, TNF- $\alpha$, IFN- $\alpha$, and $\mathrm{KC}^{7}$ These cytokines are responsible for promoting the activation, survival, migration, and differentiation of intestinal epithelial cells (IECs) and the secretion of antimicrobial peptides in IECs. ${ }^{5}$ However, exaggerated immune responses typically produce excessive cytokines and chemokines, which most likely result in colon tissue damage and tumorigenesis. ${ }^{6}$ Therefore, appropriate regulation of immune responses is imperative during clinical treatment of CACRC. Investigations into the mechanisms of CACRC development and progression will undoubtedly provide new insights into the identification of effective therapeutic strategies.

Berberine, an isoquinoline alkaloid, is a traditional Chinese herbal medicine that has been utilized in the treatment of intestinal parasitic infection and bacterial diarrhea. ${ }^{8}$ Previous studies have reported that berberine exhibits vasodilative,

\footnotetext{
${ }^{1}$ Cancer Research Center, Xiamen University Medical College, Xiamen, China and ${ }^{2}$ Jiaen Hospital, Beijing, China

Correspondence: Professor Y-y Zhan, PhD or Professor T Hu, PhD, Cancer Research Center, Xiamen University Medical College, 315 Chengyi Building, Xiangan Campus, Xiamen, Fujian 361102, China.

E-mail: thu@xmu.edu.cn or yyzhan@xmu.edu.cn

${ }^{3}$ Current address: Department of Electronic Science, Institute of Electromagnetics and Acoustics, Xiamen University, Xiamen 361005, China.

Received 8 October 2015; revised 8 May 2017; accepted 10 May 2017
} 
a

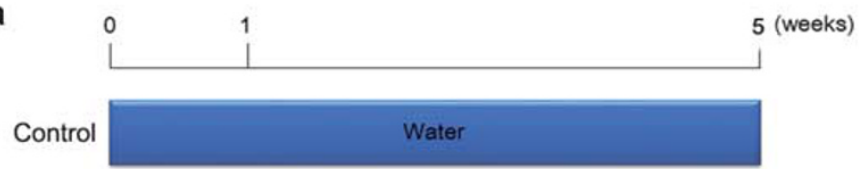

DSS

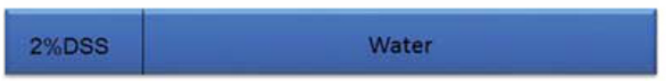

$\mathrm{DSS}+\mathrm{Be}$

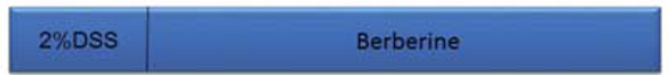

b
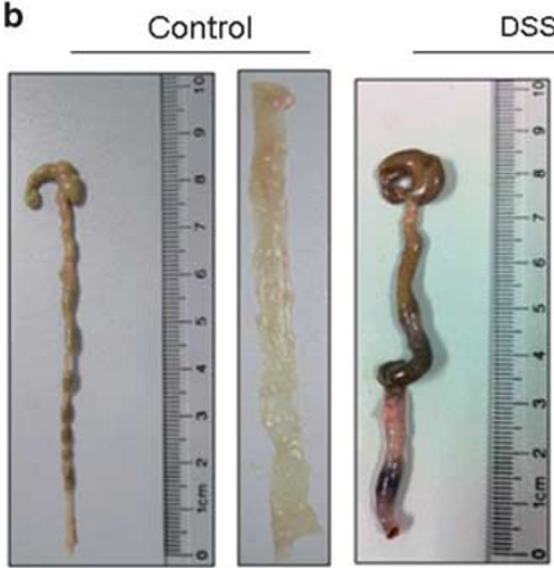

DSS

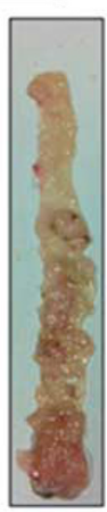

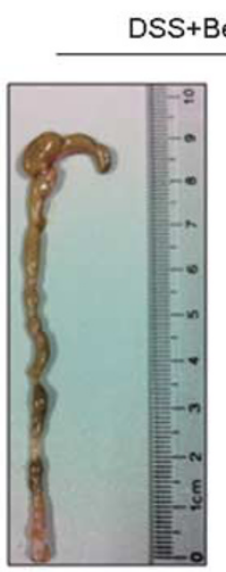

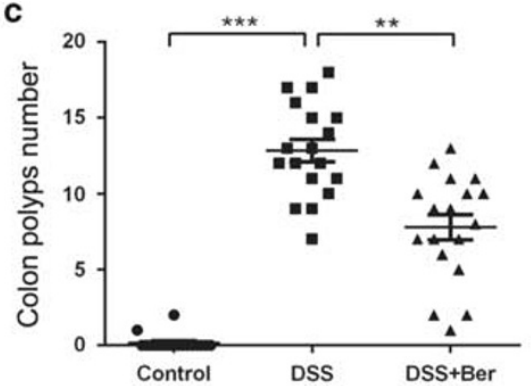

d
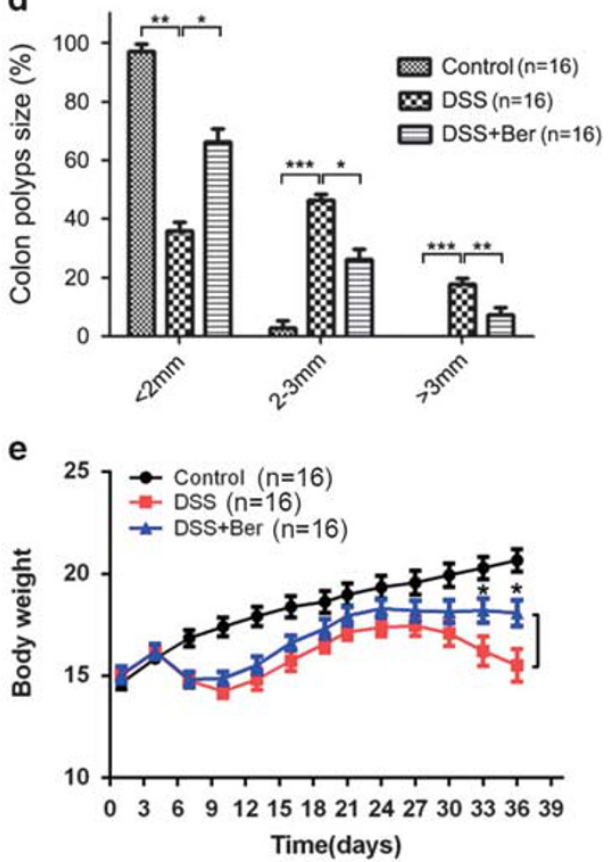

Figure 1 Berberine suppresses colon tumorigenesis in DSS-treated $A p c^{\mathrm{Min} /+}$ mice. (a) A DSS-treated $A p c^{\mathrm{Min} /+}$ mouse model. Forty-eight mice were divided into three groups: the normal control group (receiving normal drinking water for 5 weeks), the DSS-treated group (receiving DSS for 1 week and normal drinking water for an additional 4 weeks), and the DSS+ber co-treated group (receiving DSS for 1 week and berberine for an additional 4 weeks). (b) Representative images of intestinal tumor development in individual groups. (c, d) Number and size distribution of colon tumors in individual groups. (e) Body weight of mice was measured and plotted. All data are presented as the means \pm s.e.m. from at least three separate experiments. ${ }^{*} P<0.05,{ }^{*} P<0.01$, and ${ }^{* *} P<0.001$ versus control.

cholesterol-lowering, anti-convulsant, neuroprotective, and notably anti-inflammatory activities. ${ }^{9}$ Berberine suppresses inflammatory responses by promoting colonic macrophage apoptosis and decreasing pro-inflammatory cytokine production in colonic macrophages and epithelial cells in DSStreated mice. ${ }^{10}$ Recently, increasing numbers of studies have focused on the anti-tumor effect of berberine. In these studies, berberine was found to induce growth inhibition, cell cycle arrest, and apoptosis in various types of cancer cells, including leukemia, liver cancer, gastric cancer, colon cancer, and breast cancer. ${ }^{11,12}$ Moreover, our recent studies found that berberine inhibited the growth of intestinal polyps in $A p c^{\mathrm{Min} /+}$ mice and in patients with familial adenomatous polyposis. ${ }^{13}$ Berberine could also inhibit colon tumorigenesis in an azoxymethane (AOM)-initiated and DSS-promoted colorectal carcinogenesis mouse model by regulating
AMP-activated protein kinase signaling pathways. ${ }^{14}$ However, it remains unclear whether the anti-inflammatory effect of berberine contributes to its anti-tumor effect on CACRC.

In this study, we investigated the effects of berberine on colorectal tumor development in the DSS-induced chronic inflammatory microenvironment in $A p c^{\mathrm{Min} /+}$ mice and further assessed the underlying mechanisms.

\section{MATERIALS AND METHODS Reagents and Antibodies}

Dextran sulfate sodium (DSS, MP Biomedical, Solon, OH, USA) and berberine chloride (Sigma Aldrich, St. Louis, MO, USA) were prepared as reported in our previous publications. ${ }^{15}$ Antibodies against EGFR, p-EGFR (Y1173), ERK, and p-ERK were purchased from Cell Signaling Technology, Boston, MA, USA. 


\section{Animal Model}

Animal experiments were conducted in accordance with the regulations of experimental animal administration and the ethics committee of the Medical College of Xiamen University. C57BL/6J-Apc $c^{\mathrm{Min} /+}$ mice were originally obtained from Xiamen University Laboratory Animal Center. Mice were mated in monogamous pairs and housed in a temperature-controlled environment $\left(20-22^{\circ} \mathrm{C}\right)$ with a 12-h/12-h light/dark cycle. All surgeries were performed under sodium pentobarbital anesthesia, and all efforts were made to minimize suffering.

For the animal experiments shown in Figure 1, $A p c^{\mathrm{Min} /+}$ mice (4 weeks old) were divided into three groups as described in Figure 1a, including the normal control group (receiving normal drinking water for 5 weeks), DSS-treated group (receiving DSS for 1 week and normal drinking water for an additional 4 weeks), and the DSS+ber co-treated group (receiving DSS for 1 week and berberine for an additional 4 weeks). According to the method, ${ }^{16}$ colitis was induced by oral ingestion of $2 \%(\mathrm{w} / \mathrm{v})$ DSS in drinking water for 1 week. Berberine was then orally administered $(1 \mathrm{mg} / \mathrm{ml}$ in drinking water) for an additional four weeks. Then, mice were killed, and colon tissues and blood samples were obtained according to the method. ${ }^{16}$ Some colon tissue samples were fixed in $10 \%$ formaldehyde and then embedded in paraffin for histopathological study. The other samples were frozen in liquid nitrogen immediately after collection and stored at $-80^{\circ} \mathrm{C}$ until analysis. The blood samples were collected into clean dry test tubes and separated by centrifugation, and the serum was stored at $-80^{\circ} \mathrm{C}$ until use.

For the animal experiments in Figure 6, mice ( 8 weeks old) were randomly divided into five groups as described in Figure 6a. Mice were administered 2\% (w/v) DSS in drinking water for 7 days. Then, berberine and/or IL-6 treatment were administered. Berberine or its vehicle control phosphate buffer saline (PBS) was intragastrically administered at $50 \mathrm{mg} /$ $\mathrm{kg}$ body weight/day for 2 weeks of 4-day treatment and 3-day recovery followed by 2 weeks of treatment every other day. For IL-6 treatment, mice were injected intraperitoneally (i.p.) with $5 \mu \mathrm{g}$ recombinant IL-6 (Sino Biological) or its vehicle control PBS every 3 days. Mice receiving drinking water alone were used as the control. All mice were killed on day 36 to examine colon tumors. The colon tissues were collected and analyzed as mentioned above.

\section{Cell Culture}

The IMCE cell line was provided by Dr. Robert Whitehead (Vanderbilt University, Nashville, TN, USA). IMCE cells were cultured at $37^{\circ} \mathrm{C}$ with $5 \% \mathrm{CO}_{2}$ in RPMI 1640 medium supplemented with $5 \%$ heat-inactivated fetal bovine serum (FBS, HyClone, Logan, UT, USA), $5 \mathrm{U} / \mathrm{ml}$ murine IFN- $\gamma$ (Gibco, Grand Island, NY, USA), $100 \mathrm{U} / \mathrm{ml}$ penicillin (Life Technologies, Carlsbad, CA, USA), $100 \mu \mathrm{g} / \mathrm{ml}$ streptomycin (Life Technologies), $5 \mathrm{mg} / \mathrm{ml}$ insulin (Sigma Aldrich),
$5 \mathrm{mg} / \mathrm{ml}$ transferrin (Sigma Aldrich), and $5 \mathrm{ng} / \mathrm{ml}$ selenous acid (Sigma Aldrich). ${ }^{15}$

RAW 264.7 macrophages and colon cancer HCT116 cells were purchased from the Institute of Biochemistry and Cell Biology, Chinese Academy of Sciences, Shanghai, China. These cell lines were cultured at $37^{\circ} \mathrm{C}$ with $5 \% \mathrm{CO}_{2}$ in DMEM medium containing $10 \% \mathrm{FBS}, 100 \mathrm{U} / \mathrm{ml}$ of penicillin, and $100 \mu \mathrm{g} / \mathrm{ml}$ of streptomycin. ${ }^{16}$

\section{Cell Proliferation Assay}

Raw 264.7 macrophages were treated with LPS $(1 \mu \mathrm{g} / \mathrm{ml})$ in the presence or absence of berberine $(25 \mu \mathrm{M})$ for $12 \mathrm{~h}$. Culture media from Raw 264.7 cells were collected to further simulate IMCE cell proliferation. IMCE cells were seeded at a density of $10^{4}$ cells per well in 96-well plates. After adherence, cells were starved for $8 \mathrm{~h}$ in serum-free RPMI 1640 medium and then cultured in the conditioned medium collected from Raw 264.7 macrophages for an additional $24 \mathrm{~h}$. Cell proliferation was assessed by methyl thiazolyl tetrazolium (MTT) assay as described previously. ${ }^{17}$

\section{Real-Time PCR Analysis}

Total RNA was isolated from colon tissues using an RNA Isolation Kit (RNAiso plus, TaKaRa, Shiga, Japan) and then reverse transcribed using a PrimeScript RT reagent Kit (TaKaRa, Shiga, Japan). Real-time PCR was performed in a CFX96 Touch Real-Time PCR Detection System (Bio-Rad, Hercules, CA, USA) using SYBR Green PCR Master Mix (Applied Biosystems, Foster City, CA, USA). Glyceraldehyde3-phosphate dehydrogenase (GAPDH) levels were used as normalization controls. The primer sequences used are listed below:

IL-6-F: GCCTTCTTGGGACTGATGCT,

IL-6-R: TGCCATTGCACAACTCTTTTC,

TNF- $\alpha$-F: AAAAGCAAGCAGCCAACC,

TNF- $\alpha$-R: TGCCACAAGCAGGAATGA,

GAPDH-F: TGGCAAAGTGGAGATTGTTGCC,

GAPDH-R: AAGATGGTGATGGGCTTCCCG.

\section{Immunohistochemistry}

Colon tissues were fixed in 10\% formaldehyde, embedded in paraffin, and then cut into $5 \mu \mathrm{m}$ successive sections. Immunohistochemical staining was performed as previously described. ${ }^{18}$ Sections were dewaxed, incubated in $0.01 \mathrm{M}$ sodium citrate buffer for antigen retrieval, and then blocked using 5\% goat serum in PBS. After staining with the indicated antibodies overnight at $4{ }^{\circ} \mathrm{C}$, the sections were subject to an immunostaining kit (Maxim Biotech Inc, Fuzhou, China) and an DAB Substrate (Maxim, Fuzhou, China) according to the manufacturer's instructions. Photomicrographs were obtained using an Olympus BX41 microscope, and the average density of the labeling signal was measured using an image analyzer (Image-Pro Plus 5.0). 


\section{Enzyme-Linked Immunosorbent Assay (ELISA)}

IL- 6 and TNF- $\alpha$ levels in the conditioned medium of RAW 264.7 cells and serum of experimental mice were determined in triplicate using ELISA kits (R\&D System Europe, Abingdon, UK) according to the manufacturer's instructions.

\section{Western Blot Analysis}

EGFR and ERK expression and phosphorylation levels were measured using western blot in accordance with the previously reported method. ${ }^{19}$ Anti-EGFR, p-EGFR (Y1173), ERK, and p-ERK antibodies were used, and $\beta$-actin was used as the internal control.

\section{Statistical Analysis}

Statistical significance between two groups was determined by Student's $t$-test using GraphPad Prism 5.0 (GraphPad Software). $P$-values $<0.05$ were defined as statistically significant.

\section{RESULTS}

\section{Berberine Inhibited Colon Tumor Development in DSS-Treated $\mathrm{Apc}^{\mathrm{Min} /+}$ Mice}

DSS-treated $A p c^{\mathrm{Min} /+}$ mice, a widely accepted model for CACRC, were established as indicated in Figure 1a to evaluate the therapeutic effect of berberine. Mice were treated with $2 \%$ DSS for 1 week to induce colitis followed by berberine for 4 weeks (Figure 1a). At the end of week 5, mice were killed and assessed for the development of colon tumors. Compared with the control group $(0.19 \pm 0.54)$, DSS treatment obviously increased the number of colon tumors $(12.83 \pm 0.73)$; moreover, berberine treatment significantly reduced the number of tumors to $7.78 \pm 0.83$ (Figures $1 b$ and $c$ ). The diameter of the colon tumors was also greatly decreased by berberine treatment (Figure 1d). In addition, most of the colon tumors induced by DSS treatment were identified as adenocarcinoma, whereas most lesions were pre-malignant adenomatous polyps in the DSS+berberine co-treated group (Figure 2a). An increase in IEC proliferation in DSS-treated colon tissues was also observed by detecting the expression level of Ki67, a marker of cell proliferation. Berberine administration also suppressed DSS-induced hyperproliferation of IECs (Figure 2b).

Body weight recovery is one of the most important indicators in cancer therapy evaluation. The DSS-treated group exhibited two periods of body weight loss (Figure 1e). The first occurred from day 3 to day 9 due to the severe colitis induced by DSS, and the second period began at day 27 as a result of the development of colon tumors (Figure 1e). The DSS plus berberine-treated group exhibited similar body weight loss on days 3-9; however, no obvious body weight loss was observed from day 27 to day 36 .

These results therefore suggest that berberine effectively inhibited the development of CACRC.

\section{Berberine Inhibited Colon Tumor Cell Proliferation by Reducing the Production of Pro-Inflammatory Cytokines in Macrophages}

We further explored how berberine exerts its inhibitory effect on colitis-associated colorectal tumorigenesis and development. It has been reported that pro-inflammatory cytokines could stimulate cancer cell proliferation in vitro. ${ }^{20}$ The potential roles of pro-inflammatory cytokines in the development of CACRC were verified in our present experiment by treating HCT116 cells with two of the most common proinflammatory cytokines: IL- 6 and TNF- $\alpha$ (Figure 3a). We then examined whether berberine influenced the production of pro-inflammatory cytokines in DSS-treated $A p c^{\mathrm{Min} /+}$ mice by ELISA. The levels of pro-inflammatory cytokines IL- 6 and TNF- $\alpha$ in serum were dramatically increased by 10 - to 15 -fold in the DSS-induced groups, which was significantly suppressed by berberine treatment (Figures $3 b$ and $c$ ). RT-PCR analysis was also performed to detect the mRNA expression levels of IL- 6 and TNF- $\alpha$ in colon tissues. The results showed that the mRNA expression levels of colonic IL- 6 and TNF- $\alpha$ were increased significantly in DSS-treated mice, whereas this upregulation was effectively inhibited when mice were treated with berberine thereafter (Figures 3d and e). These results suggested that berberine inhibited the production of pro-inflammatory cytokines stimulated by DSS.

To investigate whether this inhibitory effect of berberine on the production of pro-inflammatory cytokines was involved in its regulation of CACRC, an in vitro cell model was used to mimic the in vivo inflammation microenvironment. Raw 264.7 macrophages were treated with LPS $(1 \mu \mathrm{g} / \mathrm{ml})$ to induce cytokine production in the presence or absence of berberine. Then, the conditioned medium was collected to simulate the proliferation of IMCE, a pre-neoplastic cell line separated from the colon epithelium of $A p c^{\mathrm{Min} /+}$ mice. ${ }^{21}$ The amount of IL-6 and TNF- $\alpha$ secreted by Raw 264.7 macrophages in the conditioned medium was first examined. LPS significantly stimulated the secretion of IL- 6 and TNF- $\alpha$ by Raw 264.7 macrophages. However, when cells were co-treated with berberine, LPS-induced IL-6, and TNF- $\alpha$ levels were greatly reduced (Figures $4 \mathrm{a}$ and $\mathrm{b}$ ). We further found that the proliferation of IMCE cells was not significantly influenced when treated with LPS directly (Figure 4c). However, the growth of IMCE cells was significantly promoted when they were cultured in the conditioned medium from LPS-stimulated Raw 264.7 cells, and this promotion was greatly attenuated when Raw 264.7 cells were co-treated with LPS and berberine (Figure 4c). These results thus indicated that berberine inhibits tumor cell proliferation by reducing the production of pro-inflammatory cytokines in the inflammatory environment.

\section{EGFR-ERK Signaling Acted Downstream of the Berberine/ Pro-Inflammatory Cytokines Axis to Regulate CACRC Cell Proliferation}

The EGFR-ERK pathway has an important role in regulating cell proliferation, ${ }^{22-24}$ so we analyzed whether this signaling 
a

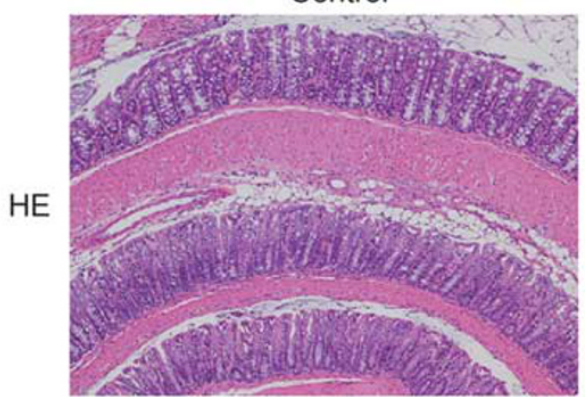

Normal

b

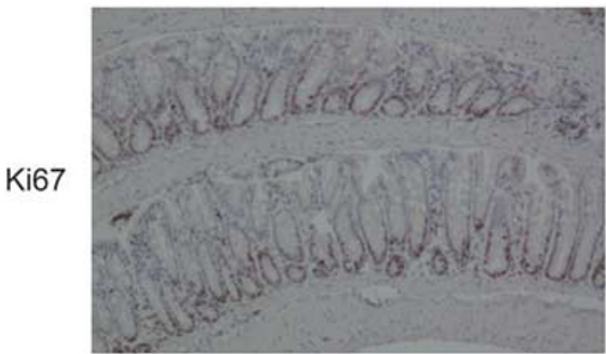

DSS

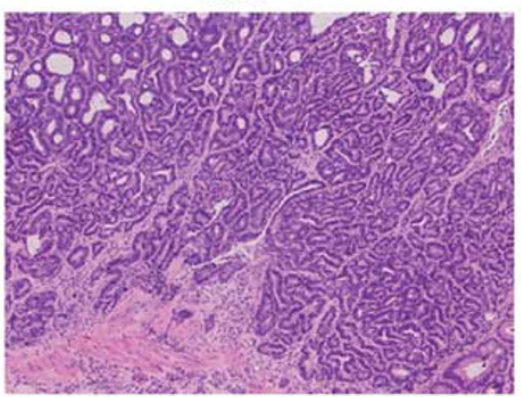

Adenocarcinoma

DSS

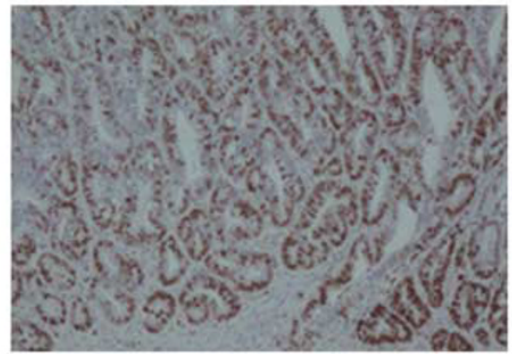

DSS+Ber

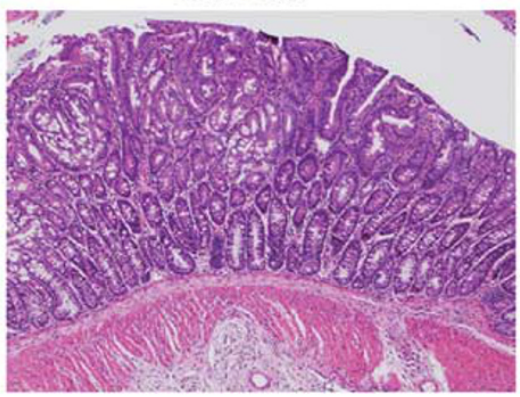

Adenomatous polyps

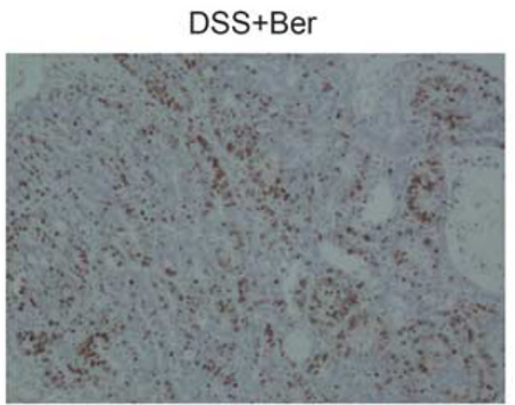

Figure 2 Histological analysis of DSS-induced polyps in $A p \mathrm{C}^{\mathrm{Min} /+}$ mice. (a) Representative histological images of colonic epithelium in individual groups. Paraffin-embedded colon tissues were stained with hematoxylin and eosin to assess the damage of colonic epithelium and the pathological type of polyps in DSS-treated $\mathrm{Apc}^{\mathrm{Min} /+}$ mice. (b) Representative immunohistochemistry (IHC) photomicrographs of colonic epithelium in individual groups. Paraffin-embedded colon tissues were stained with an anti-Ki67 antibody to determine the proliferation of colonic epithelial cells in $A p c^{\text {Min/+ }}$ mice upon different treatments.

pathway acted downstream of the berberine/pro-inflammatory cytokine axis to regulate colitis-associated carcinoma cell proliferation. Our results from the in vitro cell model as described in Figure 4c indicated that EGFR and ERK phosphorylation levels were upregulated when IMCE cells were cultured in the conditioned medium of LPS-stimulated Raw 264.7 macrophages, but were not impacted when IMCE cells were cultured in the conditioned medium of LPS and berberine co-treated Raw 264.7 cells (Figure 5a). EGFR and ERK phosphorylation levels were further analyzed in the colon tissue of DSS-treated $A p c^{\mathrm{Min} /+}$ mice by western blot and immunohistochemistry. EGFR and ERK phosphorylation levels were significantly upregulated in the colon tissues of the DSS-treated group compared with the control group. Moreover, this upregulation was effectively inhibited by berberine treatment (Figures $5 \mathrm{~b}-\mathrm{d}$ ). These results indicated that EGFR-ERK signaling was involved in regulating colitisassociated carcinoma cell proliferation downstream of the berberine/pro-inflammatory cytokines axis.

\section{IL-6 Treatment Attenuated Berberine's Effect on DSS-Treated $\mathrm{Apc}^{\mathrm{Min} /+}$ Mice}

To further prove the involvement of the suppressed pro-inflammatory cytokine/EGFR-ERK signaling axis in berberine's inhibitory effects on CACRC development in vivo, DSS-treated $A p c^{\mathrm{Min} /+}$ mice with or without berberine treatment were administrated with IL-6. To better control the doses between mice, intragastric administration and intraperitoneal injection were adopted for berberine and IL-6 treatment, respectively. However, due to the potential harm of frequent gavaging and intraperitoneal injection, mice older than those presented in Figure 1 were used. Eight-week-old mice were orally administrated with $2 \%$ DSS for 1 week to induce colitis. Then, mice were treated with berberine and/or IL-6 as indicated in Figure 6a. Four weeks later, all mice were killed, and the development of colon tumors was measured. Similar to the results in Figures $1 \mathrm{~b}-\mathrm{d}$, berberine markedly reduced the burden and diameter of colon tumors induced by DSS treatment; however, this effect of berberine was significantly attenuated by IL-6 treatment (Figures 6b-d). Most of the colon tumors induced by DSS were adenocarcinomas, whereas most lesions were pre-malignant adenomatous polyps in the berberine-treated group, which is similar to the results in Figure 2a. Nevertheless, IL-6 treatment caused a proportion of the pre-malignant adenomatous polyps in the berberine-treated group to become adenocarcinoma (Figure 6e, left panel). Moreover, berberine effectively suppressed DSS-promoted IEC proliferation, as indicated by the expression level of Ki67, whereas IL-6 treatment significantly reduced the inhibitory effect of berberine on IEC proliferation (Figure 6e, right panel). 


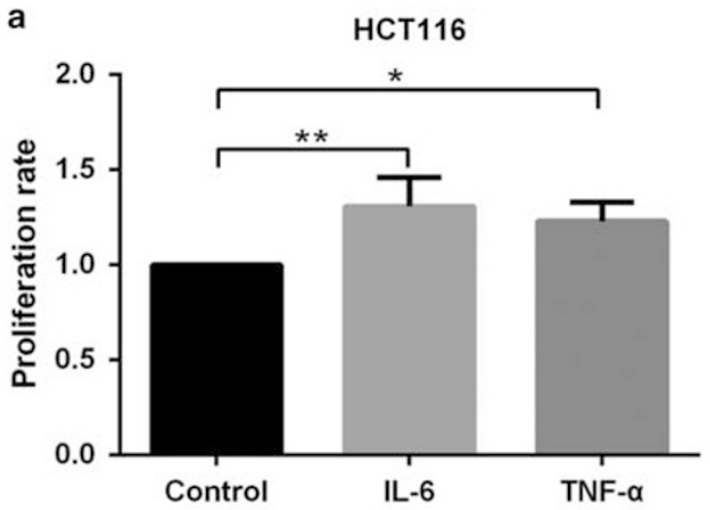

\section{b}

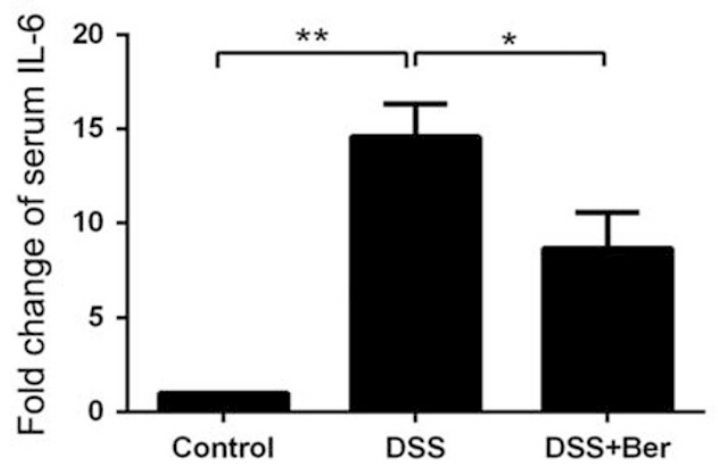

c

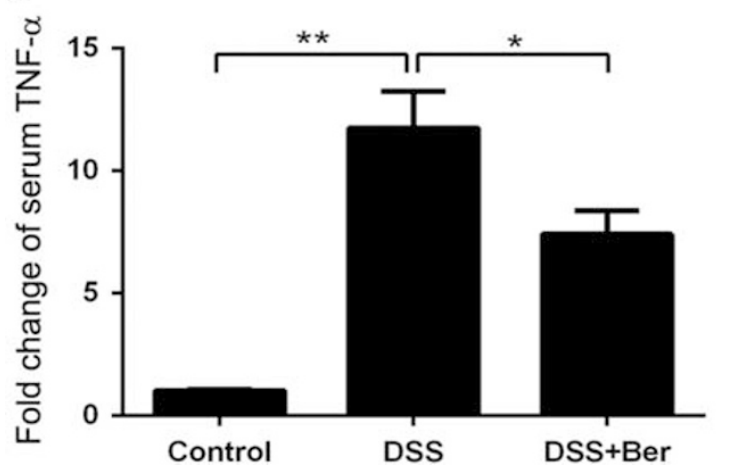

d

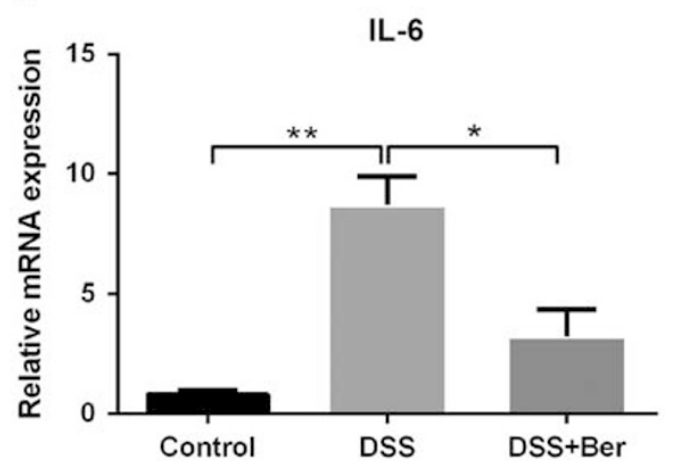

e

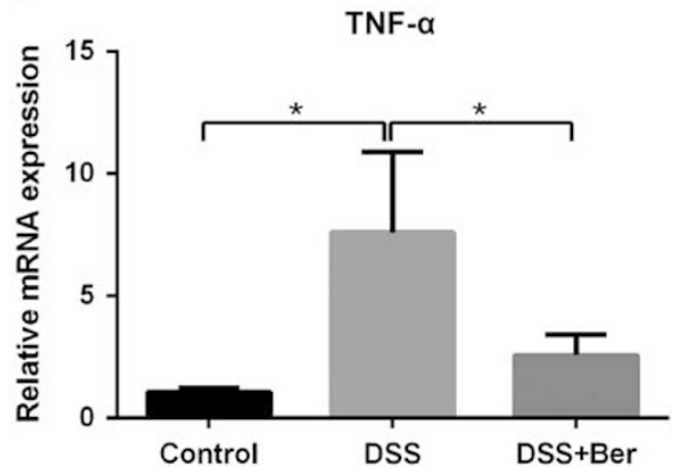

Figure 3 Berberine inhibited the production of pro-inflammatory cytokines in DSS-treated Apc ${ }^{\mathrm{Min} /+}$ mice. (a) IL- 6 and TNF- $a$ promoted the proliferation of colon cancer HCT116 cells. (b, c) IL- 6 and TNF- $a$ serum levels in $A p c^{\mathrm{Min} /+}$ mice from individual groups ( $n=16$ for each group). (d, e) IL- 6 and TNF- $a$ mRNA expression in colon tissues from individual groups was detected via real-time PCR analysis ( $n=6$ for each group). All data are presented as the means \pm s.e.m. from at least three separate experiments. ${ }^{*} P<0.05,{ }^{* *} P<0.01$ versus control.

The EGFR and ERK phosphorylation levels were further analyzed in the colon tissue of all these five groups of $A p c^{\mathrm{Min} /+}$ mice by western blot and immunohistochemistry. EGFR and ERK phosphorylation levels were greatly upregulated in DSStreated colon tissues compared with the control, which was effectively inhibited by berberine treatment; however, berberine's inhibitory effect was reduced when mice were co-treated with IL-6 (Figures $7 \mathrm{a}-\mathrm{c}$ ). Taken together, these in vivo results confirmed that berberine inhibited CACRC development at least partially via suppressing pro-inflammatory cytokine production in the colonic inflammatory microenvironment, leading to a reduction in inflammatory cytokine-activated
EGFR-ERK signaling in colorectal cancer cells and thus inhibiting CACRC.

\section{DISCUSSION}

As a traditional Chinese herbal medicine, berberine has long been used to treat intestinal parasitic infection and bacterial diarrhea. ${ }^{8}$ Berberine also exhibits beneficial effects on various types of diseases, such as reducing cholesterol levels, ${ }^{25}$ ameliorating glucose metabolism, ${ }^{26}$ and modulating Type 1 diabetes progression. ${ }^{27} \mathrm{~A}$ recent study demonstrated that berberine promotes colitis recovery and ameliorates inflammatory responses in DSS-treated mice by promoting colon 
a

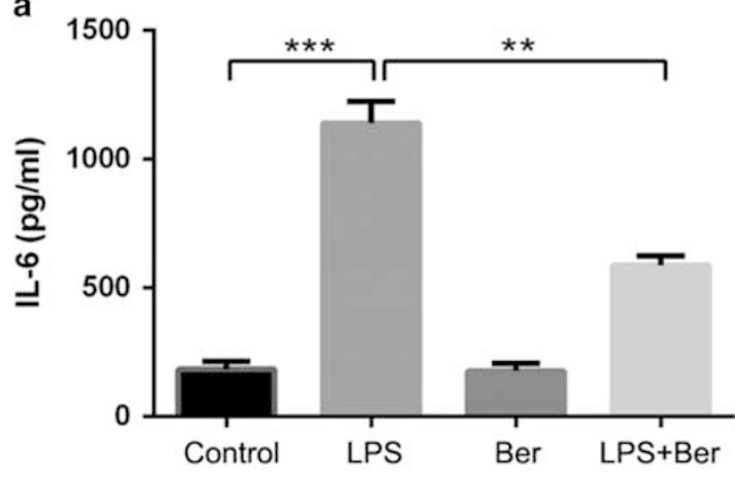

b

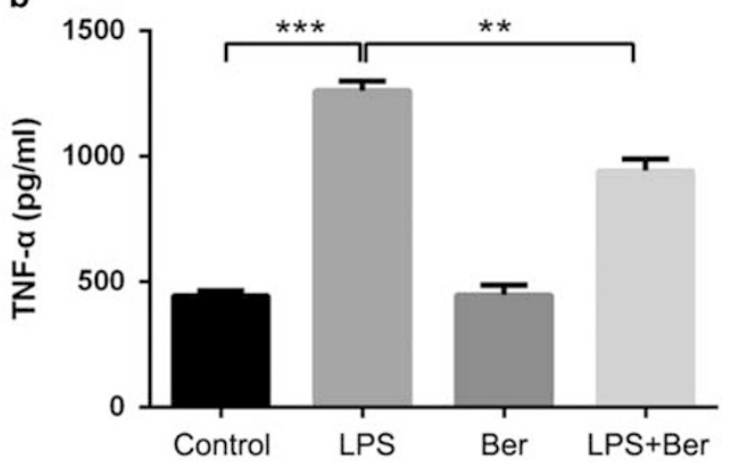

C

IMCE

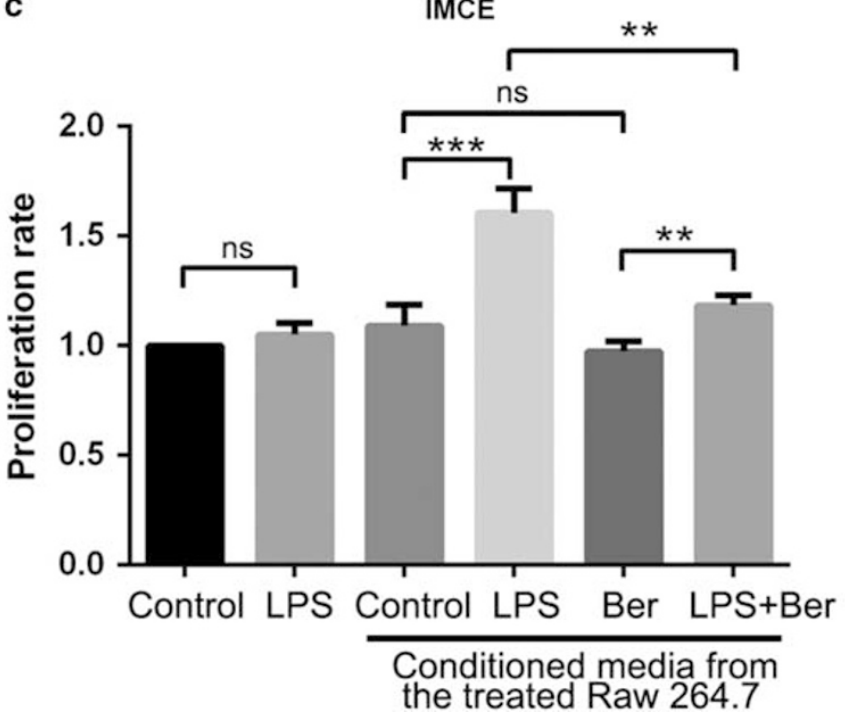

Figure 4 Berberine treatment on Raw 264.7 macrophages resulted in conditioned media with less proliferative effects on IMCE cells. (a, b) RAW 264.7 cells were treated with LPS in the presence or absence of berberine. Then, the cell culture supernatants were collected to stimulate IMCE cell proliferation. IL- 6 and TNF- $a$ levels in the supernatants of RAW 264.7 cells were measured by ELISA. (c) IMCE cells were cultured in the conditioned media from Raw 264.7 macrophages for $24 \mathrm{~h}$, and then their proliferation was determined by MTT assay. All data are presented as the means \pm s.d. from at least three separate experiments. ${ }^{*} P<0.05,{ }^{*} P<0.01,{ }^{*} * P<0.001$, and $n s$ non-significant versus control.

peritoneal macrophages apoptosis and suppressing proinflammatory cytokine production in colonic macrophages. ${ }^{10}$ The anti-tumor function of berberine was also confirmed by multiple studies. ${ }^{15,28-33}$ Berberine inhibits colon tumorigenesis in the AOM-initiated and DSS-promoted colorectal carcinogenesis mouse model via regulating AMPactivated protein kinase signaling pathways. ${ }^{14}$ Our recent studies also found that berberine could effectively suppress intestinal polyp growth in $A p c^{\mathrm{Min} /+}$ mice and in patients with familial adenomatous polyposis. ${ }^{13}$ Given that patients with IBD are more vulnerable to CACRC, there is a pressing need to better understand whether the anti-inflammatory function of berberine contributes to its anti-tumor function in CACRC. In the present study, we established a mouse model of CACRC by subjecting $A p c^{\mathrm{Min} /+}$ mice to DSS treatment and discovered that berberine exhibited advantages in CACRC treatment. Both the in vivo and in vitro studies demonstrated that berberine reduced pro-inflammatory cytokine (ie, IL-6, TNF- $\alpha$ ) production, which interfered with inflammatory response-driven EGFR signaling in tumor cell growth (Figure 8 ). These findings may provide new insights for the treatment of intestinal inflammatory-associated diseases, especially CACRC.

Colitis in DSS-treated mice mainly results from the increased cellular responses to pathogenic microbes and detrimental substances in the intestinal lumen, which leads to increasing pro-inflammatory cytokine production. ${ }^{34,35}$ On the basis of the IL- 6 and TNF- $\alpha$ profiles obtained in our study (Figure 3), there is a strong possibility that berberine could inhibit DSS-induced colon tumor development by regulating macrophage and epithelial cell-derived cytokine production. Our in vitro studies further confirmed that berberine inhibited the secretion of IL- 6 and TNF- $\alpha$ by macrophages under LPS-stimulation (Figures $4 \mathrm{a}$ and b). Similar to our result, regulation of IEC cytokine production by berberine has also been reported in the TNBS (2,6,4-trinitrobenzenesulfonic acid) model. ${ }^{28}$ As a result of the reduced stimuli, proinflammatory cytokines, tumor cell proliferation was greatly 
a

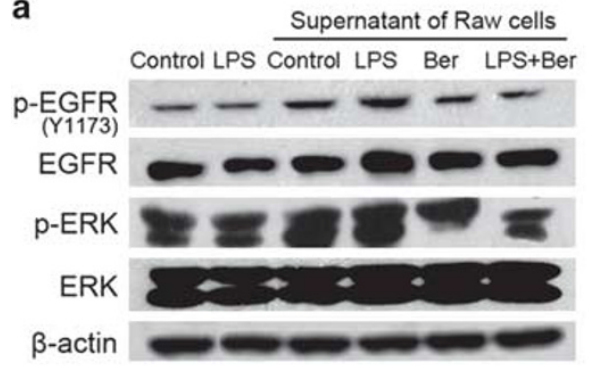

b

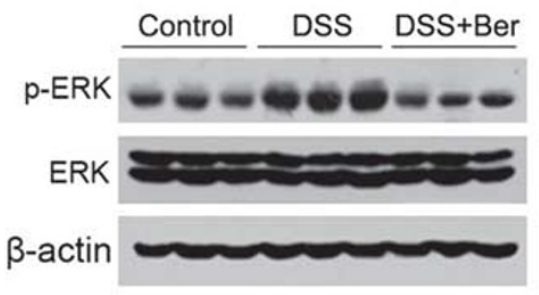

c

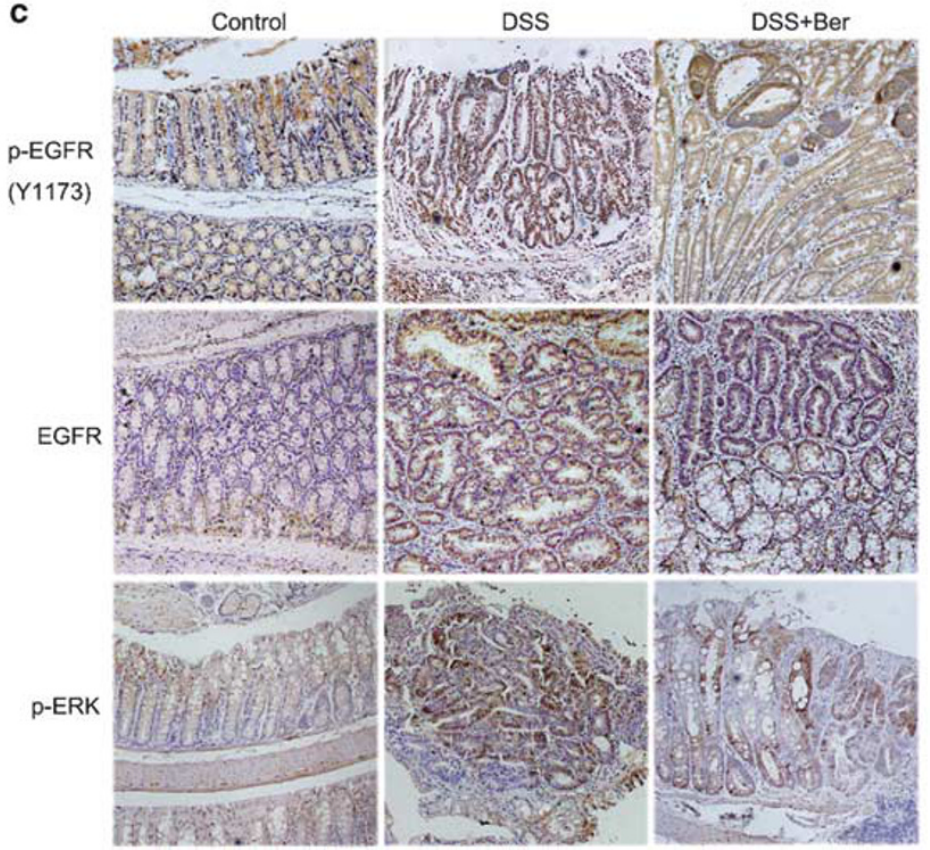

d
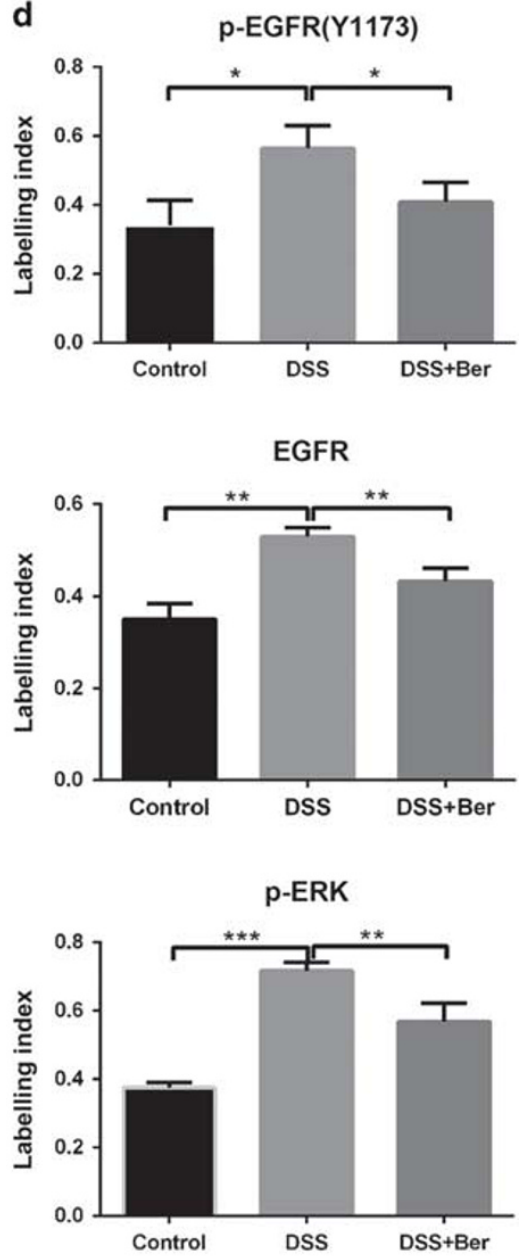

Figure 5 EGFR-ERK signaling acted downstream of the berberine/pro-inflammatory cytokine axis to regulate CACRC cell proliferation. (a) Expression and phosphorylation levels of EGFR and ERK in IMCE cells were detected by western blot. RAW 264.7 cells were stimulated with LPS in the presence or absence of berberine, and then the supernatants were collected to culture IMCE cells. Twenty-four hours later, IMCE cells were collected, lysed, and then subjected to western blot analysis. (b) ERK expression and phosphorylation levels in colon tissues were detected by western blot, and representative graphs are presented. (c, d) EGFR and ERK expression and phosphorylation levels in colon tumor specimens of Apc ${ }^{\mathrm{Min} /+}$ mice from individual groups were detected by immunohistochemistry (c) and quantified by densitometry (d). All data are presented as the means \pm s.d. from at least three separate experiments. ${ }^{*} P<0.05,{ }^{* *} P<0.01$, and ${ }^{* * *} P<0.001$ versus control.

reduced (Figure 4). We found that IMCE cell proliferation was increased when cultured in the conditioned medium of LPS-stimulated Raw 264.7 macrophages, which contained increased levels of IL-6 and TNF- $\alpha$ (Figures $4 \mathrm{a}$ and b). However, this increase in IMCE cell proliferation was markedly suppressed when cells were cultured in the conditioned medium of Raw 264.7 macrophages co-treated with LPS and berberine (Figure 4c). IMCE cell proliferation exhibited no significant change when the cells were directly treated with LPS (Figure 4c). These results suggested that berberine exhibits anti-tumor function at least partially by inhibiting pro-inflammatory cytokine production in macrophages.

Signaling pathways downstream of the berberine/proinflammatory cytokine axis that regulate tumor cell proliferation were further explored in the present study. In the process of tumorigenesis and development, multiple signaling pathways were activated, such as VEGF, Wnt, EGFR-ERK, Hedgehog, Notch, and STAT. ${ }^{36}$ Previous studies demonstrated that the activated EGFR-ERK pathway has important role in regulating cell proliferation. ${ }^{36}$ Our results revealed that EGFR phosphorylation was upregulated in both DSS-treated mouse colon tissues and IMCE cells cultured in the inflammation environment, and these effects were significantly suppressed by berberine treatment (Figure 5). In addition, EGFR pathway downstream proteins, such as ERK, were regulated in a similar mode in both DSS-induced colon tissues and IMCE cells subjected to the inflammation environment (Figure 5). Thus, we hypothesized that the EGFR-ERK signaling pathway might be a potential 
a

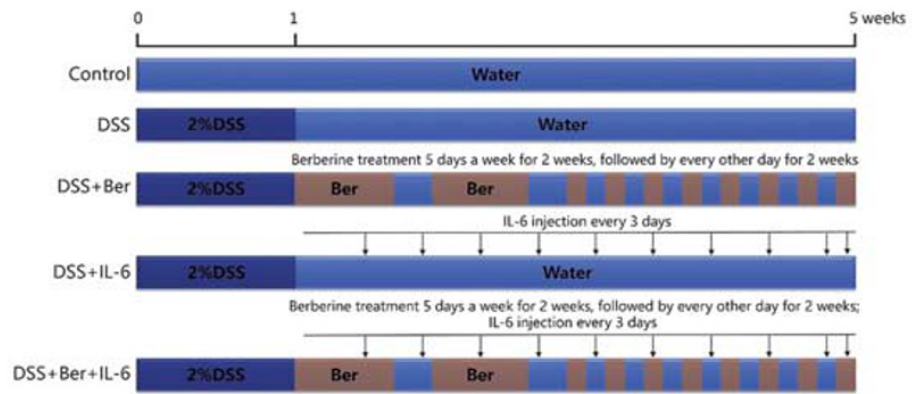

b

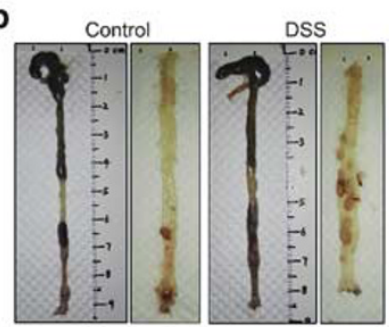

C

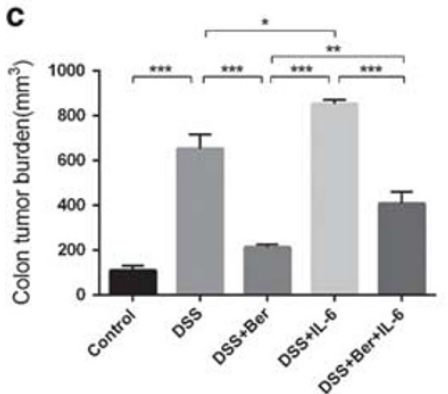

DSS+Ber

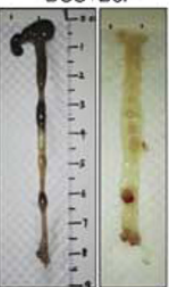

d

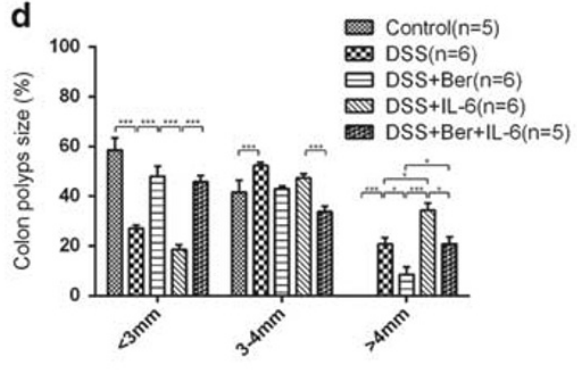

e

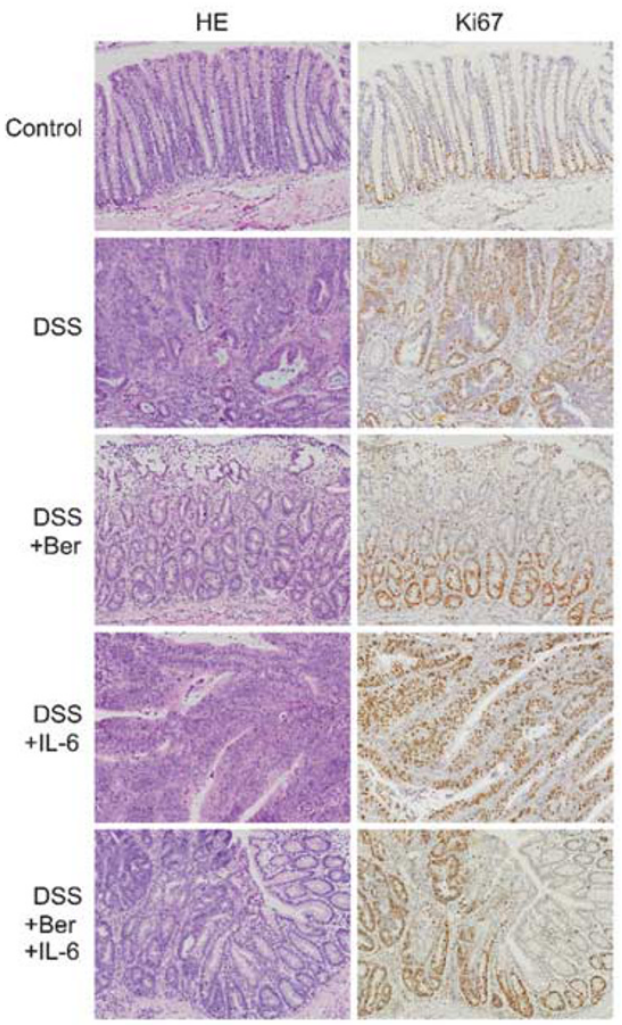

Figure 6 IL-6 treatment attenuated berberine's inhibitory effect on colon tumorigenesis in DSS-treated Apc ${ }^{\mathrm{Min} /+}$ mice. (a) A DSS-treated Apc ${ }^{\mathrm{Min} /+}$ mouse model. Thirty mice were divided into five groups, including the normal control group (receiving normal drinking water for 5 weeks), the DSS-treated group (receiving DSS for 1 week and normal drinking water for another 4 weeks), the DSS+Ber co-treated group (receiving DSS for 1 week and berberine for another 4 weeks), the DSS+IL-6 co-treated group (receiving DSS for 1 week and IL-6 for another 4 weeks), and the DSS+Ber+IL-6 cotreated group (receiving DSS 1 week, and berberine and IL-6 for another 4 weeks), as described in detail in the 'Material and Methods'. (b) Representative images of intestinal tumors that developed in individual groups. (c, d) Colon tumor burden and size distribution of colon tumors in individual groups. Tumor burden was calculated as the sum of tumor volume $\left(T_{v}=\right.$ length $\times$ width $\left.^{2}\right)$ of individual tumors in each animal. (e) Representative histological images and immunohistochemistry photomicrographs of colonic epithelium in individual groups. All data are presented as the means \pm s.e.m. from at least three separate experiments. ${ }^{*} P<0.05,{ }^{* *} P<0.01$, and ${ }^{* * *} P<0.001$ versus control.

mechanism for the berberine/pro-inflammatory cytokine axis to regulate tumor cell proliferation, which was further confirmed by our in vivo experiments (Figures 6 and 7).

Numerous studies have demonstrated that berberine exhibits anti-tumor effects via its cellular toxicity, such as suppressing proliferation and inducing apoptosis. ${ }^{11,12}$ Of note, a previous study demonstrated that berberine suppresses colon epithelial proliferation and tumorigenesis via AMPKdependent and AMPK-independent pathways in a different model of CACRC induced by AOM and DSS. ${ }^{14}$ Although both their study and our study focused on the effect of berberine on colitis-associated colon cancer, there are still many differences between them. First, different CACRC models were used. They treated female FVB mice ( 7 weeks old) with AOM to initiate tumorigenesis followed by DSS to promote tumorigenesis; by contrast, we used DSS-treated $A p c^{\mathrm{Min} /+}$ mice as our CACRC model. Second, the malignant levels of CACRC were different. Tumors in their study were pre-malignant and did not develop into adenocarcinomas; however, most of the colon tumors in DSS-treated $A p c^{\mathrm{Min} /+}$ mice were identified as adenocarcinoma in our study. Third, different molecular mechanisms (direct and indirect) were employed by berberine to inhibit CACRC. In their study, berberine was found to inhibit proliferation and induce apoptosis of colon cancer cells via AMPK-dependent inhibition of mTOR activity and AMPK-independent inhibition of $\mathrm{NF}-\kappa \mathrm{B}$, resulting in the inhibition of colon tumorigenesis (namely, direct effects on colon cancer cells). The present study found that berberine inhibits CACRC at least partially via suppressing the production of pro-inflammatory cytokines in colonic macrophages, leading to a less activated EGFR-ERK signaling pathway in colorectal cancer cells and thus inhibiting cell proliferation (namely, indirect effect on colon cancer cells, summarized in Figure 8). We admit that 
a

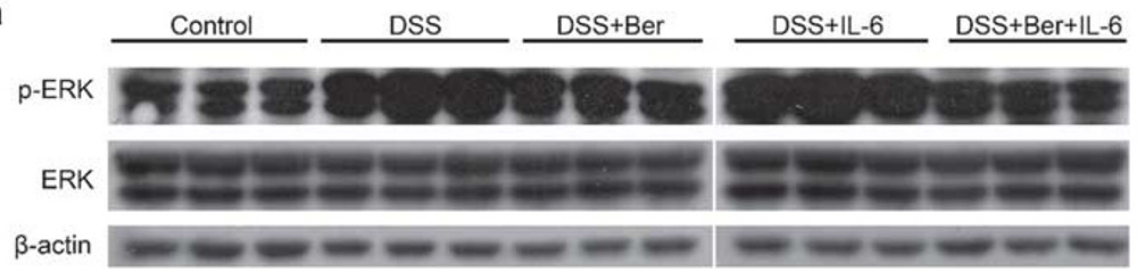

b

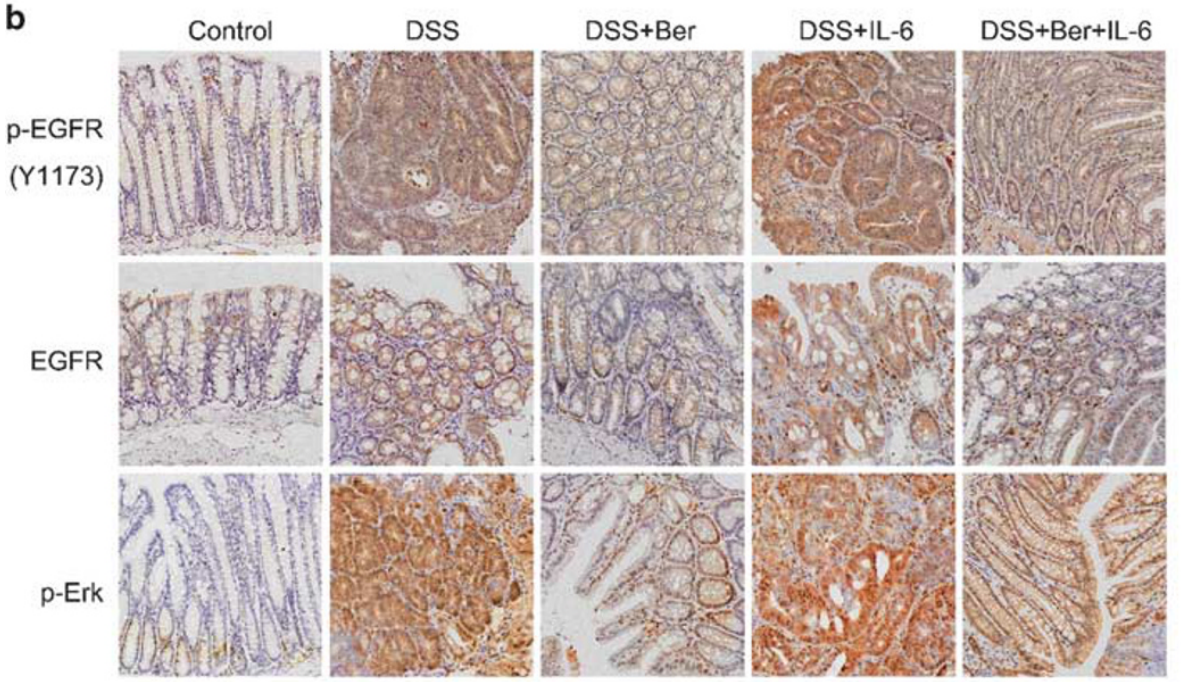

C
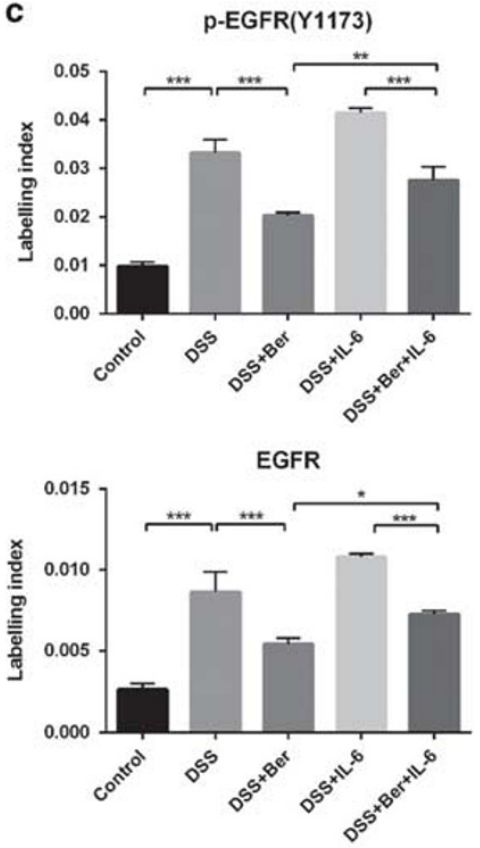

p-ERK

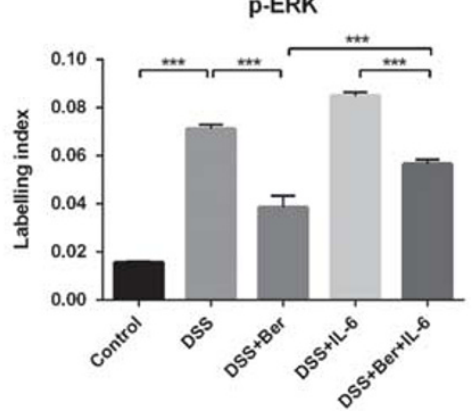

Figure 7 IL-6 treatment weakened berberine's suppressive effect on the colonic EGFR-ERK signaling pathway in DSS-treated Apc ${ }^{\text {Min/+ }}$ mice. (a) ERK expression and phosphorylation levels in colon tissues were analyzed by western blot, and representative graphs are presented. (b, c) EGFR and ERK expression and phosphorylation levels in colon tumor specimens of $A p C^{\mathrm{Min} /+}$ mice from individual groups were detected by immunohistochemistry (b) and quantified by densitometry (c). All data are presented as the means \pm s.d. from at least three separate experiments. ${ }^{*} P<0.05$, ${ }^{*} P<0.01$, and ${ }^{* *} P<0.001$ versus control.

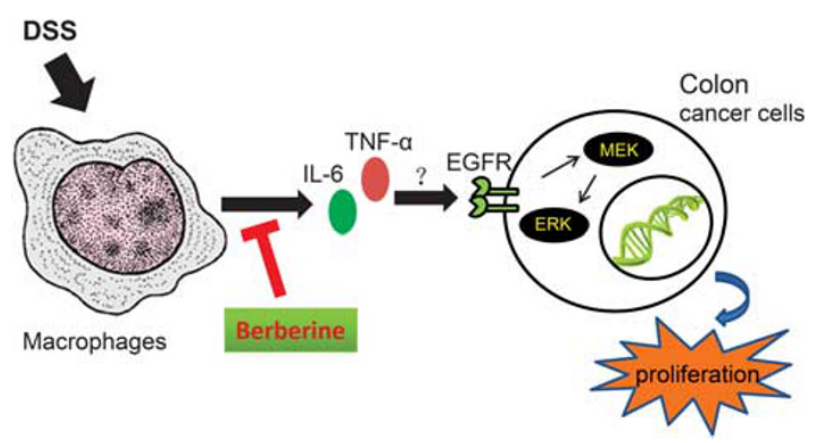

Figure 8 Proposed working model of berberine-mediated suppression of colitis-associated tumor development in DSS-treated $A p c^{\mathrm{Min} /+}$ mice.

the direct effect of berberine mentioned above may also participate in its inhibition of CACRC development in DSStreated $A p c^{\mathrm{Min} /+}$ mice. To explore whether both the indirect and the direct effects were adopted by berberine to inhibit
CACRC, DSS-treated $A p c^{\mathrm{Min} /+}$ mice with or without berberine treatment were administrated with IL-6. If the addition of IL-6 largely reverses the inhibitory effect of berberine, this suggests that berberine's effect mainly occurs through the indirect effect, namely, inhibiting cytokine generation in macrophages. By contrast, if the administration of IL-6 has a minimal effect on berberine's inhibition, this indicates that berberine acts exclusively downstream of cytokines and directly on colon cancer cells. Our results demonstrated that IL-6 treatment could significantly weaken but not completely block the inhibitory effect of berberine on CACRC (Figures 6 and 7), so we considered that both the indirect and the direct effects (anti-inflammation and cellular toxicity) of berberine contribute to its inhibitory effects on CACRC.

In summary, we have demonstrated that berberine suppresses colitis-associated tumor development in DSStreated $A p c^{\mathrm{Min} /+}$ mice. The anti-tumor effects of berberine might be mediated by the suppression of inflammatory 
responses in the colonic inflammatory microenvironment, leading to abatement of pro-inflammatory cytokine-driven EGFR signaling in tumor cell proliferation.

\section{ACKNOWLEDGMENTS}

This work was supported by grants from the National Natural Science Foundation of China (U1405228, 81472568, and 81572589), the Natural Science Foundation of Fujian Grant (2014J07010, 2017J06020, 2015R1036-1, 2017R1036-4, 2016R1034-1, and 2016R1034-4), Xiamen Science and Technology Grants (3502Z20159013), and the Fundamental Research Funds for the Central Universities (20720150058).

\section{AUTHOR CONTRIBUTIONS}

$T H$ and $Y-y . Z$ designed the experiments and wrote the manuscript. $D L, Y Z, K L$, $Y Z, B X, L X, L T, Y T, C L, W Z$, and $H C$ performed the experiments.

\section{DISCLOSURE/CONFLICT OF INTEREST}

The authors declare no conflict of interest.

1. Kirsner JB. Historical aspects of inflammatory bowel disease. J Clin Gastroenterol 1988;10:286-297.

2. Jess $T$, Gamborg M, Matzen $P$, et al. Increased risk of intestinal cancer in Crohn's disease: a meta-analysis of population-based cohort studies. Am J Gastroenterol 2005;100:2724-2729.

3. Gillen $C D$, Andrews HA, Prior $P$, et al. Crohn's disease and colorectal cancer. Gut 1994:35:651-655.

4. Gillen $C D$, Walmsley RS, Prior P, et al. Ulcerative colitis and Crohn's disease: a comparison of the colorectal cancer risk in extensive colitis. Gut 1994;35:1590-1592.

5. Terzic J, Grivennikov S, Karin E, et al. Inflammation and colon cancer. Gastroenterology 2010;138:2101-2114.

6. Sobczak M, Wlazłowski M, Zatorski H, et al. Current overview of colitisassociated colorectal cancer. Open Life Sci 2014;9:1022-1029.

7. Karin $M$, Greten FR. NF-KB: linking inflammation and immunity to cancer development and progression. Nat Rev Immunol 2005;5: 749-759.

8. Sack RB, Froehlich JL. Berberine inhibits intestinal secretory response of Vibrio cholerae and Escherichia coli enterotoxins. Infect Immun 1982;35:471-475

9. Chidambara Murthy KN, Jayaprakasha GK, Patil BS. The natural alkaloid berberine targets multiple pathways to induce cell death in cultured human colon cancer cells. Eur J Pharmacol 2012;688:14-21.

10. Yan F, Wang L, Shi Y, et al. Berberine promotes recovery of colitis and inhibits inflammatory responses in colonic macrophages and epithelial cells in DSS-treated mice. Am J Physiol Gastrointest Liver Physiol 2012:302:G504-G514.

11. Tang J, Feng Y, Tsao S, et al. Berberine and Coptidis rhizoma as novel antineoplastic agents: a review of traditional use and biomedical investigations. J Ethnopharmacol 2009;126:5-17.

12. Sun $Y, X u n K$, Wang $Y$, et al. A systematic review of the anticancer properties of berberine, a natural product from Chinese herbs. AntiCancer Drugs 2009;20:757-769.

13. Zhang J, Cao H, Zhang B, et al. Berberine potently attenuates intestinal polyps growth in ApcMin mice and familial adenomatous polyposis patients through inhibition of Wnt signalling. J Cell Mol Med 2013;17: 1484-1493.

14. Li W, Hua B, Saud SM, et al. Berberine regulates AMP-activated protein kinase signaling pathways and inhibits colon tumorigenesis in mice. Mol Carcinog 2015;54:1096-1109.

15. Wang L, Cao H, Lu N, et al. Berberine inhibits proliferation and downregulates epidermal growth factor receptor through activation of $\mathrm{Cb}$ in colon tumor cells. PLoS ONE 2013;8:e56666.

16. Li J, Zhong W, Wang W, et al. Ginsenoside metabolite compound $\mathrm{K}$ promotes recovery of dextran sulfate sodium-induced colitis and inhibits inflammatory responses by suppressing NF-kappaB activation. PLoS ONE 2014;9:e87810.

17. Song G, Chen GG, Chau DK, et al. Bid exhibits $S$ phase checkpoint activation and plays a pro-apoptotic role in response to etoposideinduced DNA damage in hepatocellular carcinoma cells. Apoptosis 2008:13:693-701.

18. Song G, Ouyang G, Mao Y, et al. Osteopontin promotes gastric cancer metastasis by augmenting cell survival and invasion through Akt-mediated HIF-1alpha up-regulation and MMP9 activation. J Cell Mol Med 2009:13:1706-1718.

19. Zhao $\mathrm{Y}$, Hou J, Mi P, et al. Exo70 is transcriptionally up-regulated by hepatic nuclear factor 4alpha and contributes to cell cycle control in hepatoma cells. Oncotarget 2016;7:9150-9162.

20. Scheibenbogen C, Mohler T, Haefele J, et al. Serum interleukin-8 (IL-8) is elevated in patients with metastatic melanoma and correlates with tumour load. Melanoma Res 1995;5:179-181.

21. Whitehead RH, Joseph JL. Derivation of conditionally immortalized cell lines containing the Min mutation from the normal colonic mucosa and other tissues of an "Immortomouse"/Min hybrid. Epithelial Cell Biol 1994;3:119-125.

22. Yu C, Zhang Z, Liao $W$, et al. The tumor-suppressor gene $N k \times 2.8$ suppresses bladder cancer proliferation through upregulation of FOXO3a and inhibition of the MEK/ERK signaling pathway. Carcinogenesis 2012;33:678-686.

23. Walther A, Johnstone E, Swanton C, et al. Genetic prognostic and predictive markers in colorectal cancer. Nat Rev Cancer 2009;9:489-499.

24. Goel GA, Kandiel A, Achkar JP, et al. Molecular pathways underlying IBD-associated colorectal neoplasia: therapeutic implications. Am J Gastroenterol 2011;106:719-730.

25. Kong W, Wei J, Abidi P, et al. Berberine is a novel cholesterol-lowering drug working through a unique mechanism distinct from statins. Nat Med 2004;10:1344-1351.

26. Xia X, Yan J, Shen Y, et al. Berberine improves glucose metabolism in diabetic rats by inhibition of hepatic gluconeogenesis. PLOS ONE 2011;6:e16556.

27. Cui $G$, Qin $X$, Zhang $Y$, et al. Berberine differentially modulates the activities of ERK, p38 MAPK, and JNK to suppress Th17 and Th1 T cell differentiation in type 1 diabetic mice. J Biol Chem 2009;284: 28420-28429.

28. Lee IA, Hyun YJ, Kim DH. Berberine ameliorates TNBS-induced colitis by inhibiting lipid peroxidation, enterobacterial growth and NF-kappaB activation. Eur J Pharmacol 2010;648:162-170.

29. Feng $\mathrm{AW}, \mathrm{Yu} C, \mathrm{Mao} \mathrm{Q}$, et al. Berberine hydrochloride attenuates cyclooxygenase-2 expression in rat small intestinal mucosa during acute endotoxemia. Fitoterapia 2011;82:976-982.

30. Jiang $Q$, Liu $\mathrm{P}, \mathrm{Wu} \mathrm{X}$, et al. Berberine attenuates lipopolysaccharideinduced extracelluar matrix accumulation and inflammation in rat mesangial cells: involvement of NF-kappaB signaling pathway. Mol Cell Endocrinol 2011;331:34-40.

31. Wang $\mathrm{L}$, Liu L, Shi Y, et al. Berberine induces caspase-independent cell death in colon tumor cells through activation of apoptosisinducing factor. PLoS ONE 2012;7:e36418.

32. Lan $\mathrm{T}, \mathrm{Wu} T$, Chen $\mathrm{C}$, et al. Berberine attenuates high glucose-induced proliferation and extracellular matrix accumulation in mesangial cells: involvement of suppression of cell cycle progression and NF-kappaB/ AP-1 pathways. Mol Cell Endocrinol 2014;384:109-116.

33. Li MH, Zhang YJ, Yu YH, et al. Berberine improves pressure overloadinduced cardiac hypertrophy and dysfunction through enhanced autophagy. Eur J Pharmacol 2014;728:67-76.

34. Kitajima S, Takuma S, Morimoto M. Changes in colonic mucosal permeability in mouse colitis induced with dextran sulfate sodium. Exp Anim 1999;48:137-143.

35. Egger B, Bajaj-Elliott M, MacDonald TT, et al. Characterisation of acute murine dextran sodium sulphate colitis: cytokine profile and dose dependency. Digestion 2000;62:240-248.

36. Wang Q, Du H, Geng G, et al. Matrine inhibits proliferation and induces apoptosis via BID-mediated mitochondrial pathway in esophageal cancer cells. Mol Biol Rep 2014;41:3009-3020. 